\title{
Flexural Behavior of Prestressed Steel-Concrete Composite Members with Discontinuous Webs
}

\author{
Jae Yuel Oh, Deuck Hang Lee, Sang Hum Cho, Hyun Kang, \\ Hae-Chang Cho, and Kang Su Kim \\ Department of Architectural Engineering, University of Seoul, 90 Jeonnong-dong, Dongdaemun-gu, \\ Seoul 130-743, Republic of Korea \\ Correspondence should be addressed to Kang Su Kim; kangkim@uos.ac.kr
}

Received 1 April 2015; Accepted 28 May 2015

Academic Editor: Ana S. Guimarães

Copyright (C) 2015 Jae Yuel Oh et al. This is an open access article distributed under the Creative Commons Attribution License, which permits unrestricted use, distribution, and reproduction in any medium, provided the original work is properly cited.

\begin{abstract}
The corrugated webbed prestressed (CWPS) composite member was developed to improve the efficiency of the prestress introduced into the steel beam, and experimental studies were performed to examine its structural behavior. Additionally, a unified analysis model that can estimate the nonlinear flexural behavior of the composite member and the accordion effect of the corrugated webbed steel beams at the prestressing stage was proposed. As a consecutive experimental series, in this study, the discontinuous-webbed prestressed (DWPS) composite member was developed, and this innovative composite member can reduce the amount of steel materials used, compared with the former CWPS composite member. Flexural tests were carried out to investigate their structural performances, and their behaviors were analyzed in detail by a nonlinear finite element analysis.
\end{abstract}

\section{Introduction}

Many studies have been actively conducted to use steel materials more effectively, and particularly studies on innovatively designed steel members have been conducted by some research groups, as shown in Figure 1. For example, the research group of the ATLSS Research Center at Lehigh University proposed various types of innovative steel and composite members [1-3], and some of them were actually applied to bridge and building construction. As the steel structure can be vulnerable to vibration, buckling, and fire, steel-concrete composite systems are often used to overcome such disadvantages $[4,5]$. Among composite members, prestressed composite members can provide active control of strength, ductility, and serviceability, and consequently, their applications have recently grown on many construction sites [6-8]. The introduction efficiency of prestress in a typical steel beam is, however, very low due to its high axial stiffness, and the large out-of-plane deformation along the weak axis of the steel section during prestressing is another concern. In authors' previous studies $[9,10]$, as shown in Figure 2(a), the corrugated webbed prestressed (CWPS) composite member was introduced to overcome these disadvantages, which improves the introduction efficiency of prestress using the accordion effect. A mechanical analysis model was also developed to estimate the accordion effect at the prestressing stage and the flexural behavior of the CWPS member [9].

The fabrication of such a corrugated web, however, is somewhat costly, leading us to modify it one step further. In this study, therefore, the corrugated webs were replaced with discontinuous steel plates, as shown in Figure 2(b), which can also fully use the accordion effect. Flexural tests were conducted on the discontinuous-webbed prestressed (DWPS) composite members, and their flexural behaviors were evaluated in detail by nonlinear finite element analysis (NLFEA).

\section{Experimental Program}

2.1. Test Specimens. The dimensional details of the test specimens before and after composite action are shown in Figure 3, which are identical to the specimens in the authors' previous study $[11,12]$ except for the shape of steel webs. The section heights of the test specimens before and after 


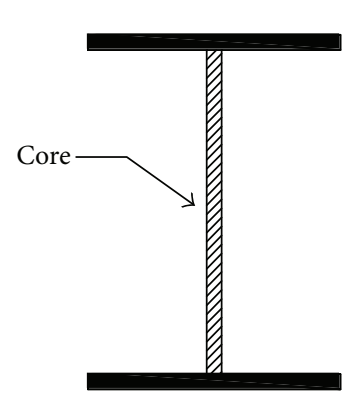

Composite web

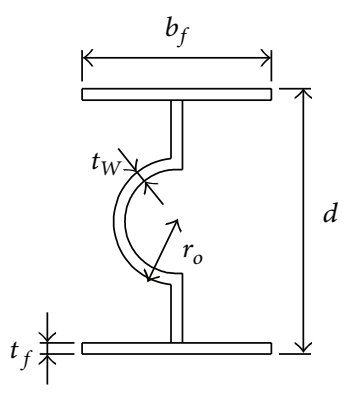

One-arc corrugation

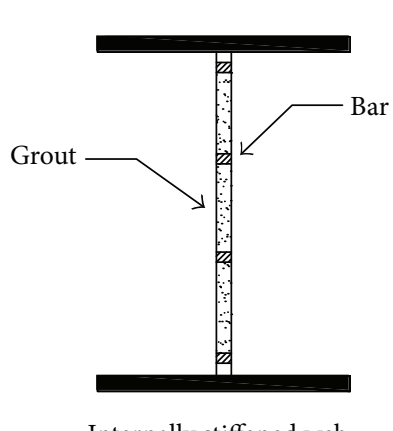

Internally stiffened web

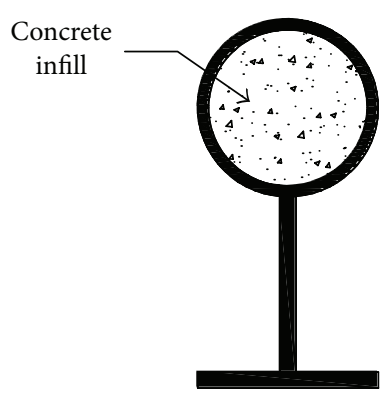

Tubular flange

(a) Steel beam with composite section

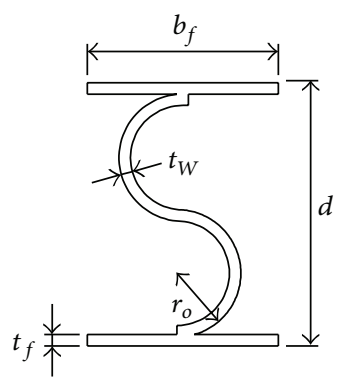

Two-arcs corrugation

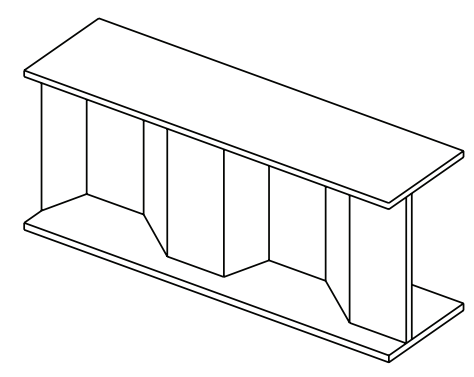

Trapezoidal corrugation

(b) Steel beam with corrugated webs

FIGURE 1: Various innovative steel and composite members.

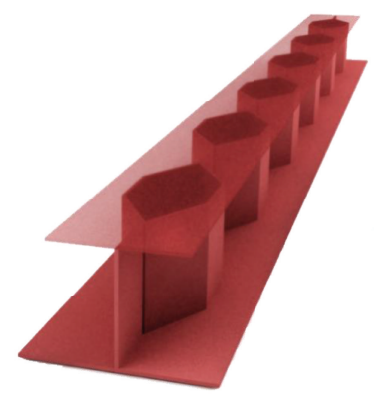

Before composite

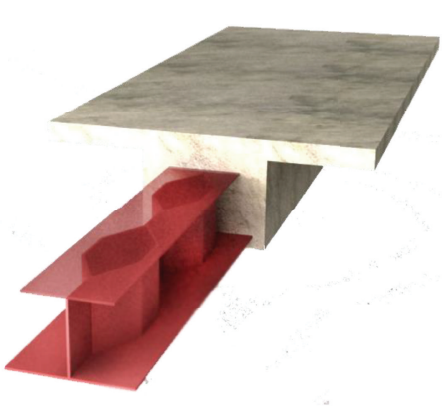

After composite

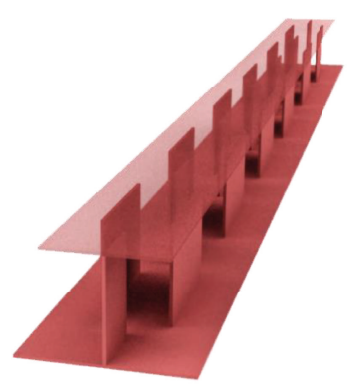

Before composite

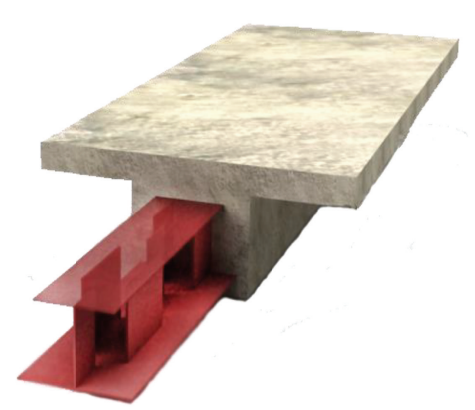

After composite

(a) Steel beam with corrugated webs

(b) Steel beam with discontinuous webs

FIGURE 2: Various types of steel beams with innovative steel plate webs.

composite were $373 \mathrm{~mm}$ and $470 \mathrm{~mm}$, respectively. The steel beam has an asymmetric section, and the width of the top and bottom flanges was $200 \mathrm{~mm}$ and $300 \mathrm{~mm}$, respectively. The discontinuous steel web plates were welded on the bottom flange first and, then, subsequently welded on the top flange. The width and thickness of the concrete slab of the composite section were $1100 \mathrm{~mm}$ and $140 \mathrm{~mm}$, respectively. In total, two specimens were tested in this study, and both test specimens had the same dimensional and material properties except for the web openings, as illustrated in Figures 3(b) and 3(c). The test program was divided into two stages: the stage of prestress introduction into the naked steel beam with discontinuous webs before the composite action and the stage of flexural tests on the simply supported DWPS composite beam specimens. As shown in Figure 3(c), there was no web opening in specimen FP1, while three openings were intentionally introduced in the FP2 specimen. The openings were located at the center and $L / 4(1430 \mathrm{~mm})$ away from both end supports of specimen FP2, and their dimensions were $150 \mathrm{~mm}$ and $100 \mathrm{~mm}$ in height, respectively, and $150 \mathrm{~mm}$ in width.

2.2. Material Properties and Test Procedures. The concrete used for the test specimens was type 1 Portland cement, and crushed granite stones with a maximum size of $25 \mathrm{~mm}$ were 


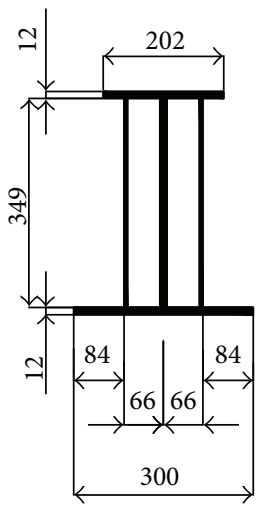

Before composite action

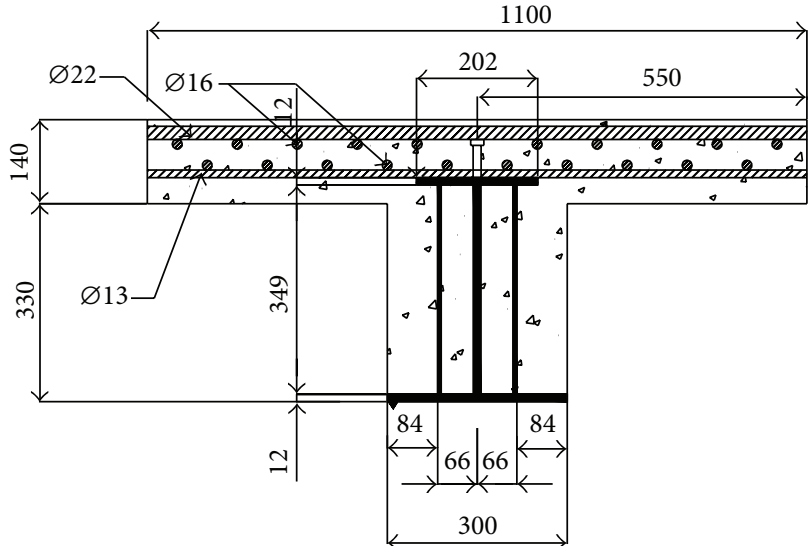

After composite action

(a) Sectional details of specimens

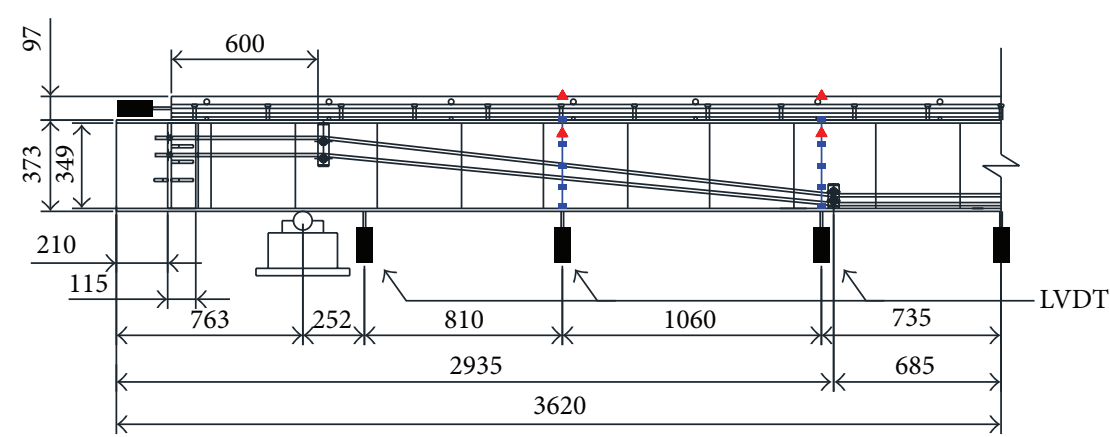

- Steel strain gauge

- Concrete strain gauge

(b) Specimen FP1

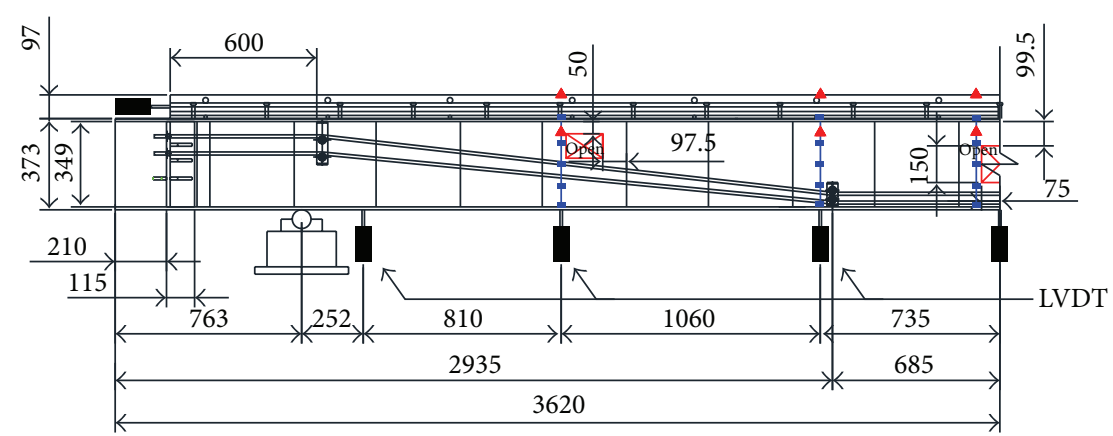

- Steel strain gauge

- Concrete strain gauge

(c) Specimen FP2

FIGURE 3: Details of test specimens and measurements.

used as the coarse aggregate. The concrete mix was designed to achieve $30 \mathrm{MPa}$ in compressive strength with a water-tocement (W/C) ratio of $44.2 \%$, and the details of the concrete mix proportions are summarized in Table 1 . The flanges of the steel beam were all $12 \mathrm{~mm}$ thick, and the discontinuous webs were $12 \mathrm{~mm}$ thick for the one-plate section parts and $6 \mathrm{~mm}$ thick for the two-plate parts (Figure 3), respectively, for which SS400 steel was used. Seven-wire low-relaxation tendons of $12.6 \mathrm{~mm}$ in diameter were used for all specimens, and their ultimate tensile strength $\left(f_{p u}\right)$ was $1860 \mathrm{MPa}$. The material tests on the prestressing tendons were carried out in accordance with the ASTM Standard A370. The material test results of the prestressing steels including the concrete and the steel plates are summarized in Table 2 . The average 
TABLE 1: Concrete mix proportion.

\begin{tabular}{|c|c|c|c|c|c|c|c|c|}
\hline \multirow{2}{*}{ Design strength $(\mathrm{MPa})$} & \multirow{2}{*}{$\mathrm{G}_{\max }(\mathrm{mm})$} & \multirow{2}{*}{$\mathrm{W} / \mathrm{C}(\%)$} & \multirow{2}{*}{ S/A (\%) } & \multicolumn{5}{|c|}{ Unit volume weight $\left(\mathrm{kg} / \mathrm{m}^{3}\right)$} \\
\hline & & & & W & $\mathrm{C}$ & S & G & $\mathrm{AD} 2$ \\
\hline 30 & 25 & 44.2 & 46.9 & 165 & 373 & 837 & 966 & 1.87 \\
\hline
\end{tabular}

TABLE 2: Material properties.

\begin{tabular}{|c|c|c|c|c|c|c|c|c|}
\hline \multirow{3}{*}{ Specimen } & \multicolumn{4}{|c|}{ Steel plate (SS400) } & \multicolumn{2}{|c|}{ Concrete } & \multicolumn{2}{|c|}{ Tendon } \\
\hline & \multicolumn{2}{|c|}{$6 \mathrm{~mm}$} & \multicolumn{2}{|c|}{$12 \mathrm{~mm}$} & & & & \\
\hline & $f_{y}(\mathrm{MPa})$ & $E_{\text {st }}(\mathrm{MPa})$ & $f_{y}(\mathrm{MPa})$ & $E_{\text {st }}(\mathrm{MPa})$ & $f_{c}^{\prime}(\mathrm{MPa})$ & $E_{c}(\mathrm{MPa})$ & $f_{p u}(\mathrm{MPa})$ & $A_{\mathrm{ps}}\left(\mathrm{mm}^{2}\right)$ \\
\hline $\begin{array}{l}\text { FP1 } \\
\text { FP2 }\end{array}$ & 268 & $2.0 \times 10^{5}$ & 273 & $2.0 \times 10^{5}$ & 34 & 26,994 & 1,860 & 98.2 \\
\hline
\end{tabular}

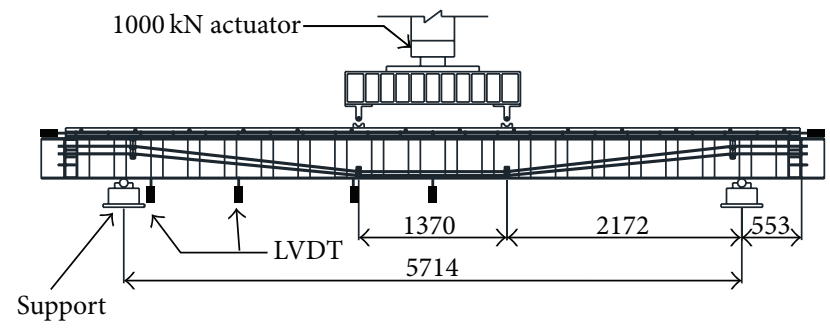

Figure 4: Test setup.

compressive strength of the concrete $\left(f_{c}^{\prime}\right)$ was $34.4 \mathrm{MPa}$, and the strain at the compressive strength of concrete $\left(\varepsilon_{c}^{\prime}\right)$ was about 0.0025 . The yield strengths of $6 \mathrm{~mm}$ and $12 \mathrm{~mm}$ steel plates were $268 \mathrm{MPa}$ and $273 \mathrm{MPa}$, respectively. As shown in Figure 4, the DWPS composite beam specimens were tested under two-point loading condition with a displacement loading rate of $0.005 \mathrm{~mm} / \mathrm{s}$. The test specimens were simply supported with a net span length of $5720 \mathrm{~mm}$, and the distance from the end supports to the loading points was $2860 \mathrm{~mm}$.

2.3. Measurements. As illustrated in Figures 3 and 4, four LVDTs were installed at the soffit of the test specimens to measure the vertical deflections, and each LVDT was also installed on both ends in the longitudinal direction to measure the slippage between the concrete slab and the steel beam. As shown in Figures 3(b) and 3(c), the strain gauges were installed at the center, the loading point, and the midpoint between the support and the loading point of the test specimens to measure the longitudinal strain distribution along the member height, and additional strain gauges were also installed on the prestressing tendons.

\section{Nonlinear Finite Element Analysis}

For the detailed evaluation of global and local behavior of the test specimens, nonlinear finite element analyses (NLFEA) were carried out using ABAQUS, commercially available software, and the computational procedures are summarized in Figure 5. In this section, the analysis method considering the nonlinearity of the materials is explained in detail together with the modeling strategies of the prestress transfer mechanism and the composition of concrete with the deformed steel beam due to prestress. Also, the structural behaviors of the DWPS composite beams were analyzed, and the analysis results were compared with the test results.

3.1. Modeling and Material Properties. As shown in Figure 6, a quarter of the test specimen was modeled because of its symmetric geometry. The steel beam, the prestressing tendon, and the concrete were modeled using 3D solid elements. The mesh size-sensitivity checks were conducted, from which the proper mesh size has been determined as $50 \mathrm{~mm}$, corresponding to 1476 elements. Other detailed information on the mesh size-sensitivity analysis of finite element modeling can be found elsewhere [10]. Because the geometry of the DWPS composite beam is quite complex, the eight-node C3D8R element was selected among the hexahedron (brick) $3 \mathrm{D}$ solid elements to improve the convergence of the iterative calculations and the accuracy of the nonlinear analysis [13]. It is noted that the initial stress or deformation in tendons due to prestress could not be modeled by using the wire elements in the ABAQUS platform because of the geometric characteristics of draped tendon layout and the construction sequences. Thus, the solid elements were inevitably adopted in this study especially for the finite element modeling of the prestressing tendons. For the reinforcing bars, a two-node T3D2 3D truss element was adopted to simplify the modeling and reduce the analysis time [14]. The elastoperfectly plastic behavior was assumed for the constitutive relationships of the reinforcing bars and the steel plates, as follows:

$$
\begin{aligned}
& f_{s}=E_{s} \varepsilon_{s} \leq f_{y}, \\
& F_{s}=E_{\mathrm{st}} \varepsilon_{\mathrm{st}} \leq F_{y},
\end{aligned}
$$

where $f_{s}, \varepsilon_{s}, E_{s}$, and $f_{y}$ are the stress, the strain, the modulus of elasticity, and the yield strength of the reinforcing bars, respectively, and $F_{s}, \varepsilon_{\mathrm{st}}, E_{\mathrm{st}}$, and $F_{y}$ are the stress, the strain, the modulus of elasticity, and the yield strength of the steel plates, respectively. The modified Ramberg-Osgood model 


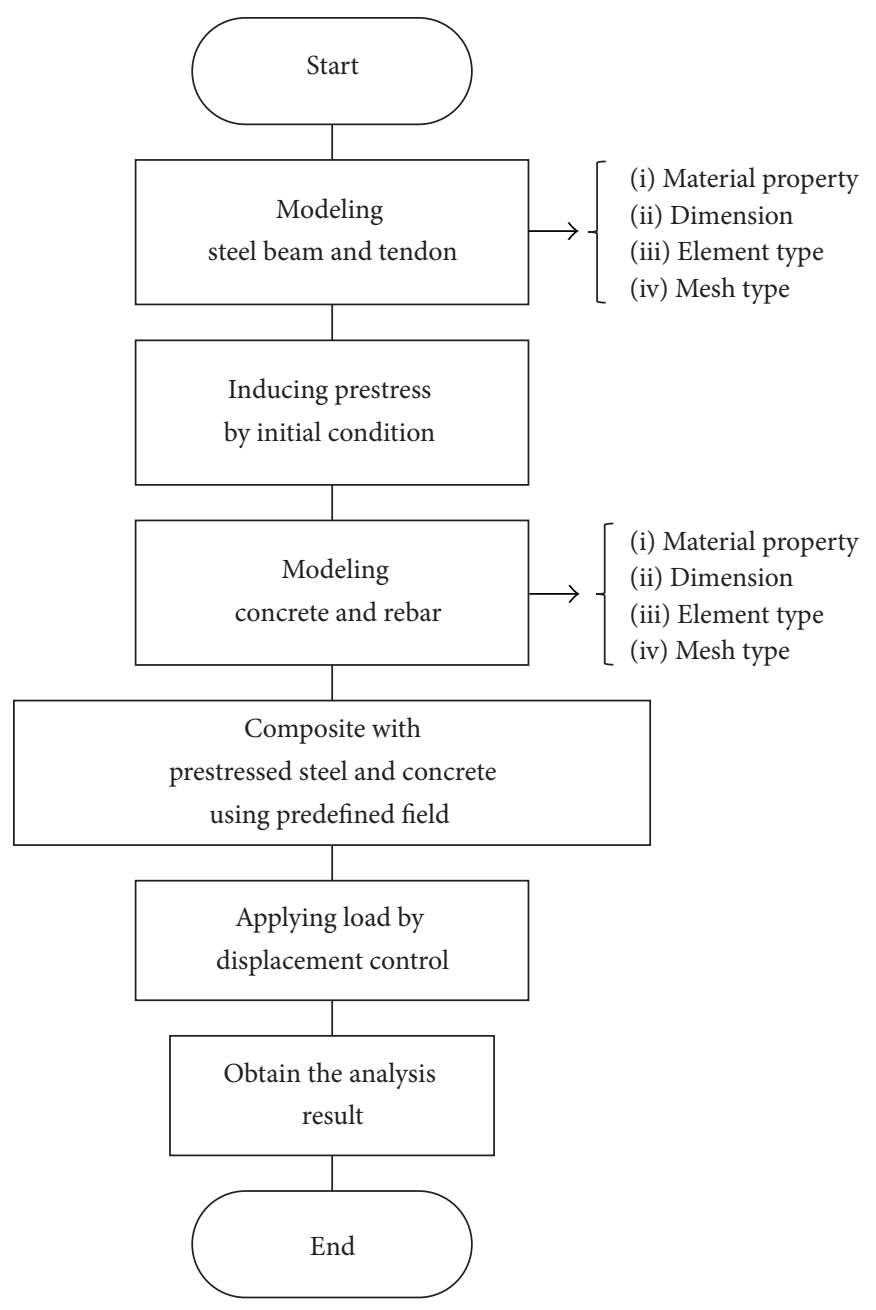

FIGURE 5: Summary of computational procedures.

was used as a constitutive model of the prestressing tendon [15], which can be expressed, as follows:

$$
f_{\mathrm{ps}}=E_{\mathrm{ps}} \varepsilon_{\mathrm{ps}}\left\{0.03+\frac{0.975}{\left[1+\left(118 \varepsilon_{\mathrm{ps}}\right) 10\right]^{0.1}}\right\} \leq f_{p u},
$$

where $f_{\mathrm{ps}}, \varepsilon_{\mathrm{ps}}, E_{\mathrm{ps}}$, and $f_{p u}$ are the stress, the strain, the modulus of elasticity, and the tensile strength of the prestressing tendons, respectively. The concrete damaged plasticity (CDP) model, adopting the Drucker-Prager criterion, was used to properly consider the confining effect, the material nonlinearity of the concrete under compressive stress, and biaxial tension-softening behavior of the concrete. The constant values of the dilation angle $(\psi)$, the eccentricity $(e)$, and viscosity parameter $(\mu)$ were assumed to be $52.9^{\circ}, 0.1$, and 0 , respectively. Additionally, the ratio of the initial equibiaxial compressive yield stress to initial uniaxial compressive yield stress $\left(f_{b 0} / f_{c 0}\right)$ was applied as 1.16 , based on Kupfer's test results [16] and Arab et al's study [17]. To determine the damage properties and the inelastic strains on the concrete in compression and tension, Vecchio and Collins's model was adopted as the uniaxial stress-strain relationship of the concrete in compression and tension, respectively, as follows [18]:

$$
\begin{aligned}
& f_{c}=f_{c}^{\prime}\left[2\left(\frac{\varepsilon_{c}}{\varepsilon_{c}^{\prime}}\right)-\left(\frac{\varepsilon_{c}}{\varepsilon_{c}^{\prime}}\right)^{2}\right], \\
& f_{c 1}=\frac{f_{\mathrm{cr}}}{1+\sqrt{200 \varepsilon_{1}}},
\end{aligned}
$$

where $f_{c}$ and $\varepsilon_{c}$ are the compressive stress and strain of concrete, respectively, and $f_{c}^{\prime}$ and $\varepsilon_{c}^{\prime}$ are the compressive strength and the corresponding strain of concrete, respectively. $f_{c 1}$ and $\varepsilon_{c 1}$ are the tensile stress and strain of concrete, respectively, and $f_{\mathrm{cr}}$ is the biaxial cracking strength, taken to be $0.33 \sqrt{f_{c}^{\prime}}$. The stress-strain curves of materials are shown in Figure 7.

3.2. Prestressing Stage before the Composite Action. The DWPS composite members tested in this study were fabricated through three steps: (1) introduction of prestress into the naked steel beam, (2) formwork on sides of the steel beam, and (3) placement of the concrete on the initially 


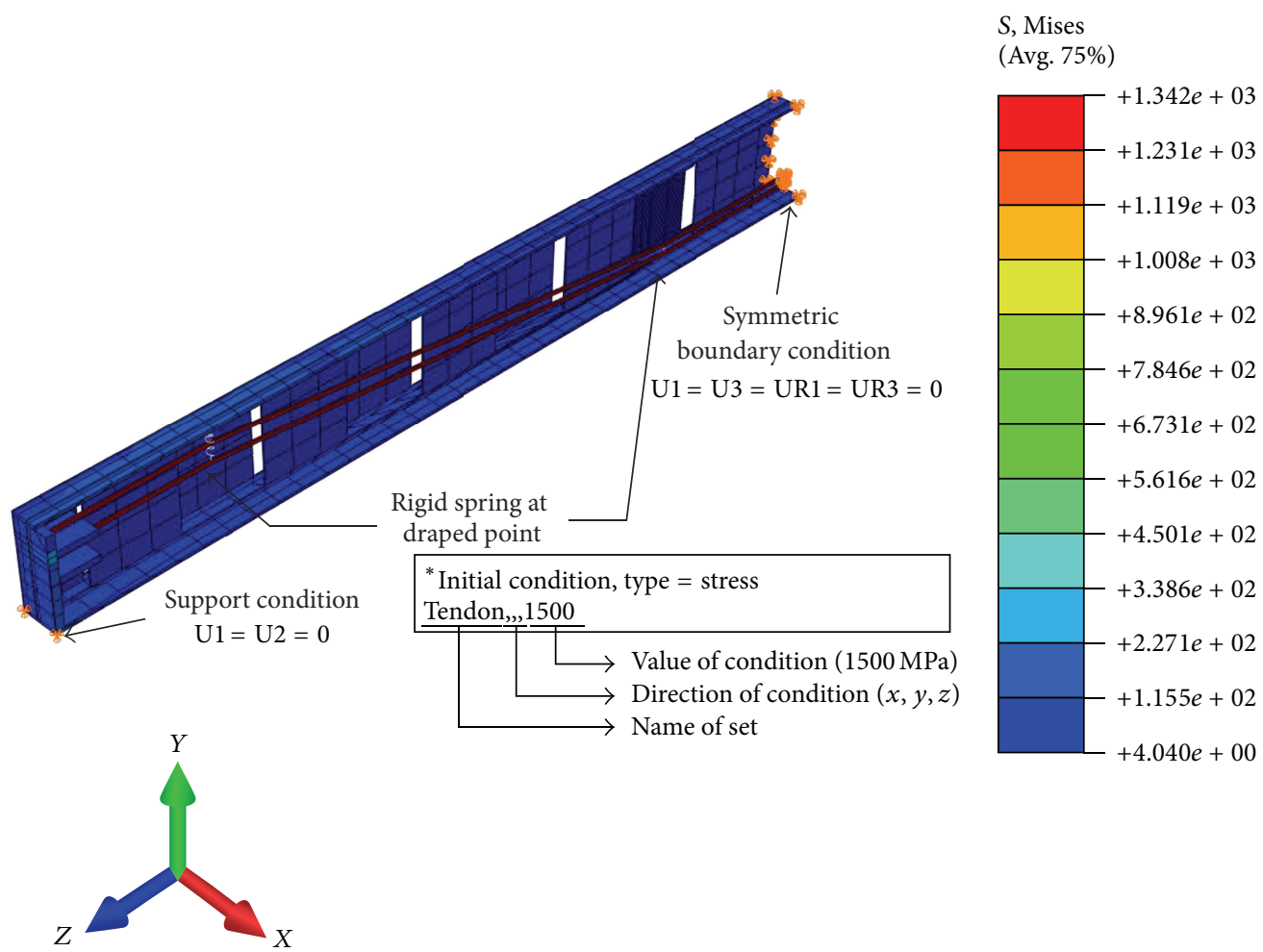

FIGURE 6: FE modeling of prestressing stage by initial condition method.

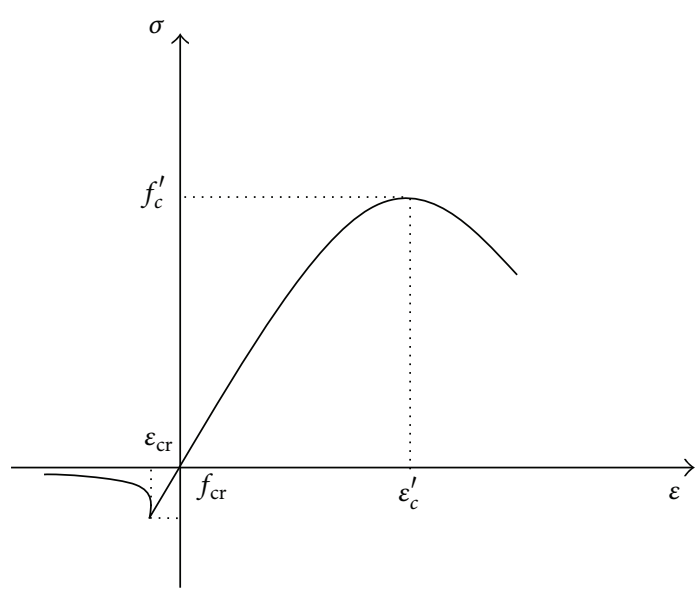

(a) Concrete

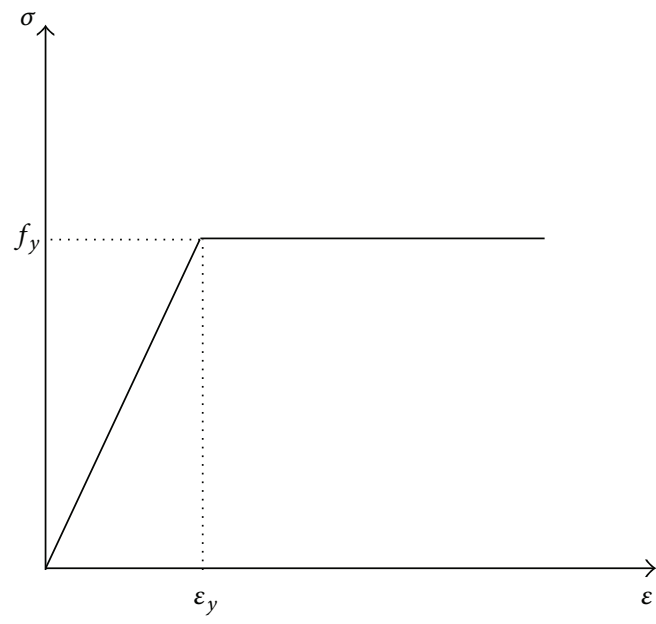

(b) Steel

FIGURE 7: Stress-strain curves of materials.

deformed steel beam due to the prestress. Thus, the construction sequences need to be properly considered in modeling for an accurate evaluation of the structural behaviors of the DWPS composite beams. For the FE modeling of the prestress transfer mechanism, the interaction between the prestressing tendons and the steel beam should be taken into account properly as well. As illustrated in Figure 6, the nodes at the end of the prestressing tendons were constrained on the anchorage plate by the node-to-surface condition. The draped prestressing tendons were also constrained on the steel saddle idealized by a spring element with infinite stiffness. The prestresses and deformations induced in the steel beam before the composite action were reflected on the DWPS composite beams using the initial condition. The initial condition option enables the user to give initial values of stresses or strains to the specific element group in the ABAQUS platform. By giving a certain magnitude of stress to the prestressing tendons as an initial condition, then the prestresses are automatically introduced into the steel beam in the following loading stage. In Figure 6, the first line in 


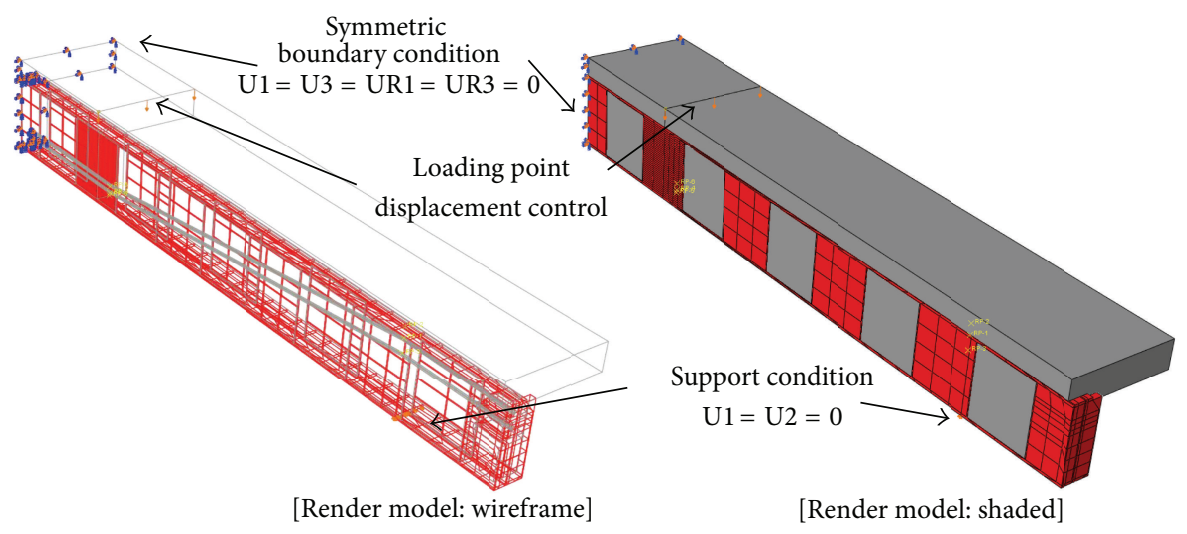

FIGURE 8: FE modeling after composite action using the predefined option.

the input script represents the command to assign the initial condition type, and in this study, the stress type was selected. “Tendon,,1500" in the second command line means the name of the set to be considered, the directions of the initial condition $(x, y$, and $z$ ), and the corresponding magnitudes, respectively. Considering the prestress loss due to the elastic shortening of the steel beam, $1500 \mathrm{MPa}$ of the initial stress was applied to secure the level of the effective prestress $\left(f_{\mathrm{pe}}\right)$ to be $70 \%$ of the tensile strength of tendons $\left(0.7 f_{p u}\right)$. The magnitude of the effective prestress estimated by the finite element analysis was about $1300 \mathrm{MPa}$, quite similar to the measured value of $1264 \mathrm{MPa}$.

3.3. Behavior after Composite Action. To properly reflect the initial stresses and deformations induced in the steel beam due to the prestress in the nonlinear finite element analysis of the DWPS beam member after composite action, the predefined field approach based on orphan mesh [14] was used. The analysis result file with odb extension provided by ABAQUS software, which was obtained from the analysis of the prestress introduction to the naked steel beam with discontinuous webs explained in the previous section, was imported as the orphan mesh. Then, the imported stress and strains were used as the predefined initial conditions of the steel beam and the prestressing tendons in the subsequent analysis of the DWPS beam after composite action. This orphan mesh approach, using the predefined field, allowed us to combine the steel beam or prestressing tendons with the concrete without any stress or deformation in concrete, as illustrated in Figure 8. Because the steel beam has axial deformation and an initial upward camber due to the prestressing force $\left(P_{e}=f_{\mathrm{pe}} A_{\mathrm{ps}}\right)$ and the eccentric moment $\left(P_{e} e\right)$ before composite action, some parts of the deformed steel beam may overlap with surrounding concrete, or the inevitable gaps at contact surfaces between the concrete and the steel beam would be formed. To prevent such problems, the interaction condition of the contact surfaces between the steel beam and the surrounding concrete was imposed using the concept of a master-slave algorithm [12]. Also, the gaps between the steel beam and the surrounding concrete were

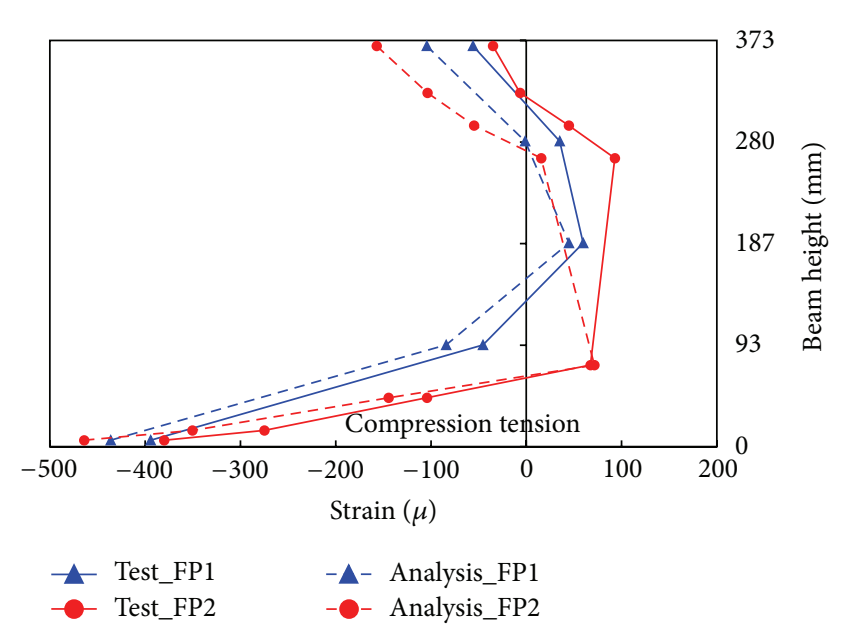

FIGURE 9: Strain distribution along the member heights.

resolved by controlling the tolerance with the adjustment zone option, and the level of the allowable tolerance was set to be capable of accommodating the maximum value of the initial axial deformation and the vertical camber obtained from the analysis results at the prestressing stage.

\section{Comparison of Test and Simulation Results}

4.1. Prestressing Stage of Steel Beam with Discontinuous Webs before the Composite Action. As mentioned, the magnitude of the effective prestress in the prestressing tendons was initially intended to be $0.7 f_{p u}$, and that measured from the load cell was $0.68 f_{p u}$ due to the prestress loss caused by the anchorage seating and the elastic shortening. The effective prestressing force $\left(P_{e}\right)$ corresponding to the effective prestress was $122.1 \mathrm{kN}$. In Figure 9, the strain distributions induced by the prestress along the member heights measured at the center section of the naked steel beam before composite action and those estimated by FEA are compared. It was confirmed that, due to the accordion effect, strains hardly developed in the steel web plate, and the large strains were 


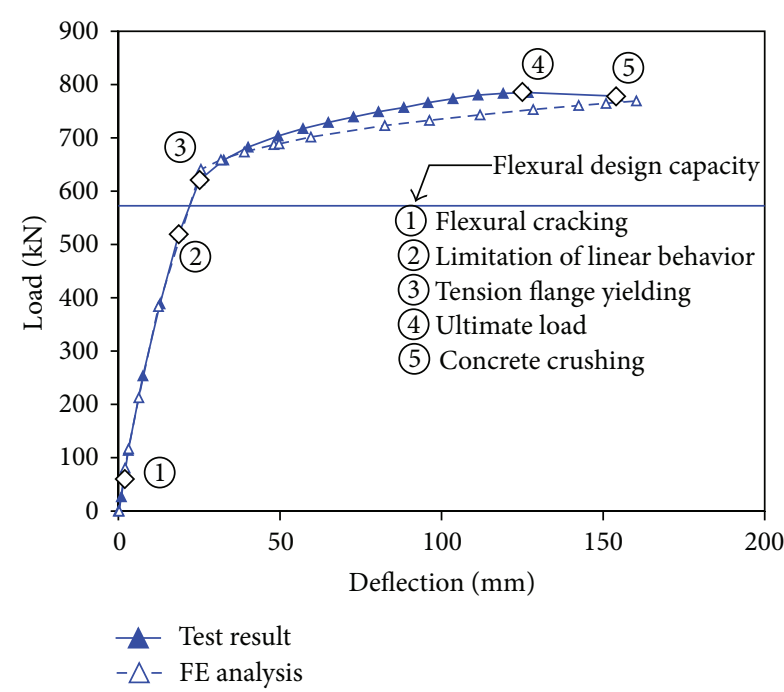

(a) FP1 specimen

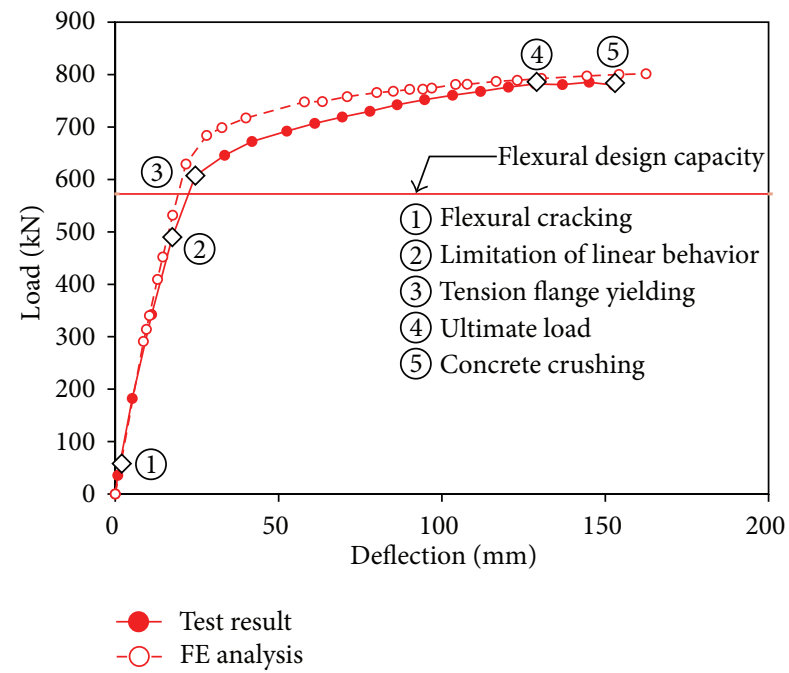

(b) FP2 specimen

FIGURE 10: Measured and estimated load-displacement responses of test specimens.

measured at the top and bottom flanges, which were the main flexural resistance elements. However, small tensile strains were measured in the web plate, although it was subjected to the compressive force by the prestressing tendons, which seems to be due to the stress disturbance near the mid-height of web plates. Similar behaviors were also obtained from FEA results. When the compressive force is introduced by the prestressing tendons, the compressive force cannot be transferred continuously because the web plates are distributed discontinuously, and the forces can only be transmitted through the top and bottom flanges. Because of this unique behavioral characteristic, the compressive stresses introduced into the top and bottom flanges increase.

As explained in our previous report [11], the axial stiffness and flexural stiffness of the steel beam with corrugated webs are reduced by the accordion effect, and therefore, the stresses introduced to the top and bottom steel flanges become larger than those of the conventional wide flange steel beam. To reflect the reduction in the axial and flexural stiffness by the accordion effect, the concepts of the effective moment of inertia $\left(I_{\text {eff }}=\eta_{f} I_{g}\right)$ and the effective area $\left(A_{\text {eff }}=A_{\text {flange }}+\right.$ $\eta_{a} A_{\text {web }}$ ) were introduced, and the coefficients of the effective moment of inertia $\left(\eta_{f}\right)$ and the effective web area $\left(\eta_{a}\right)$ were proposed, respectively, as follows:

$$
\begin{aligned}
& \eta_{a}=0.30\left[\left(\frac{d}{t_{w}}\right)^{0.19}\left(\frac{a}{h_{w}}\right)^{0.19}\left(\frac{b_{f}}{h_{w}}\right)^{0.56}\right], \\
& \eta_{f}=0.70\left(\frac{d}{t_{w}} \frac{a}{h_{w}} \frac{b_{f}}{h_{w}}\right)^{0.15},
\end{aligned}
$$

where $d, t_{w}, a, h_{w}$, and $b_{f}$ are the wave height, the web thickness, the panel width, the web height, and the bottom flange width, respectively. To determine the effective coefficients $\left(\eta_{a}\right.$ and $\left.\eta_{f}\right)$ for the discontinuous-webbed steel beams, parametric studies were conducted here on a total of
24 FE models, as in Kim and Lee's study [11]. The analysis results showed that the coefficients of effective moment of inertia $\left(\eta_{f}\right)$ and effective web area $\left(\eta_{a}\right)$ of the CWPS and DWPS composite members were almost identical. On this basis, the strain and stress behavior of the steel beam with discontinuous webs at the prestressing stage can be estimated, considering the accordion effect, as follows:

$$
\begin{aligned}
& \varepsilon_{\mathrm{pe}, t}=\frac{\sigma_{t}}{E_{s}}=-\frac{P_{e}}{E_{s} A_{\mathrm{eff}}}+\frac{P_{e} e}{E_{s} I_{\mathrm{eff}}} y_{t}-\frac{M_{d}}{E_{s} I_{\mathrm{eff}}} y_{t}, \\
& \varepsilon_{\mathrm{pe}, b}=\frac{\sigma_{b}}{E_{s}}=-\frac{P_{e}}{E_{s} A_{\mathrm{eff}}}+\frac{P_{e} e}{E_{s} I_{\mathrm{eff}}} y_{b}-\frac{M_{d}}{E_{s} I_{\mathrm{eff}}} y_{b},
\end{aligned}
$$

where $\varepsilon_{\mathrm{pe}, t}$ and $\varepsilon_{\mathrm{pe}, b}$ are the effective prestrains in the top and bottom flanges of the steel beam, respectively, $\sigma_{t}$ and $\sigma_{b}$ are the stresses on the top and bottom fibers of the section, respectively, $P_{e}$ is the effective prestressing force, $E_{s}$ is the elastic modulus of the steel plate, $A_{g}$ and $I_{g}$ are the area and the moment of inertia of gross section, respectively, $e$ is the eccentricity of the tendon from the centroid of the gross section at the maximum moment region, $M_{d}$ is the dead load moment, and $y_{t}$ and $y_{b}$ are the distances from the top and bottom fibers of the section to the centroid of the gross section, respectively.

4.2. Behavior of Composite Member with Discontinuous Webs. Figures 10(a) and 10(b) show the load-displacement responses of specimens FP1 and FP2 and those estimated by NLFEA. For specimen FP1, the initial flexural cracks were observed at $58 \mathrm{kN}$ ( $2 \mathrm{~mm}$ vertical deflection at mid-span of the specimen). At the load level of $393 \mathrm{kN}$ (13 mm deflection at mid-span), the cracks propagated into the concrete slab, and, at a load level of $589 \mathrm{kN}$ ( $23 \mathrm{~mm}$ deflection at mid-span), the stiffness of the load-displacement curve was reduced with shear cracking at the support region. At a load level of $687 \mathrm{kN}$ (43 $\mathrm{mm}$ deflection at mid-span), horizontal shear cracks 

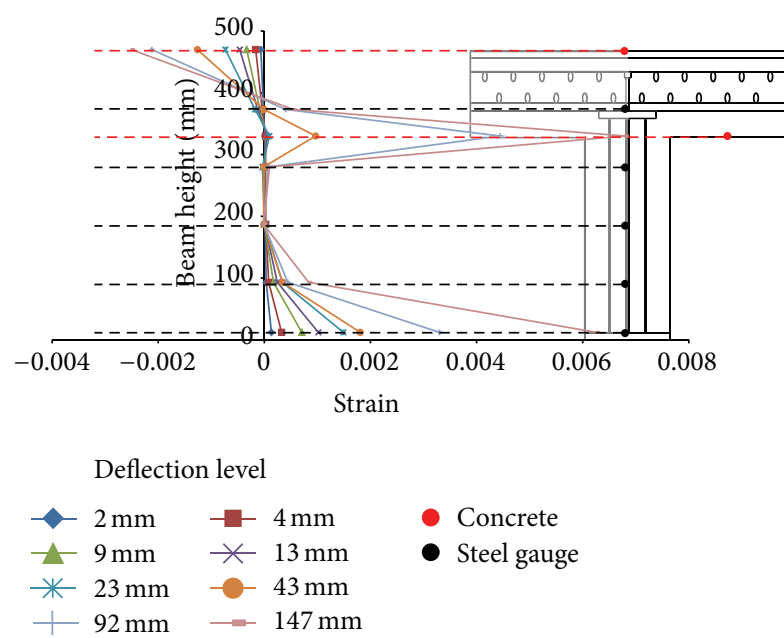

(a) Test results

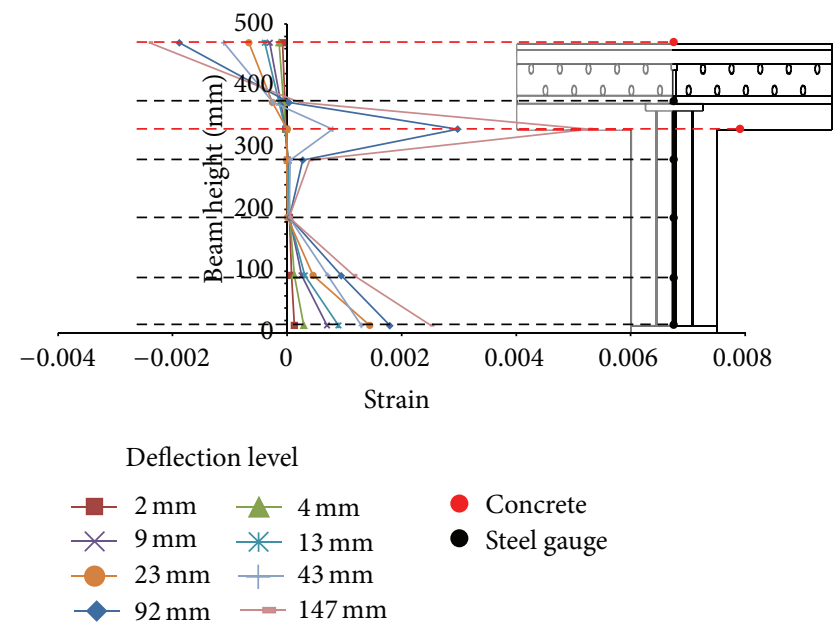

(b) FE analysis

FIGURE 11: Strain distribution along the sectional heights of specimen FP1.

between the concrete slab and the top flange of the steel beam were observed, and small pieces of the concrete slab near the loading point were delaminated. Thereafter, the displacement of the specimen increased rapidly due to yielding of the bottom flange of the steel beam, and the maximum load was measured as $785 \mathrm{kN}$, and the FP1 specimen failed at a deflection of $147 \mathrm{~mm}$ in flexure, at which the concrete in the compression zone was crushed. Similar behavioral patterns of the load-deflection responses were observed in specimen FP2 having the web openings. Flexural cracks were observed at $68 \mathrm{kN}$ ( $2 \mathrm{~mm}$ deflection at mid-span), and these flexural cracks developed into the concrete slab at $539 \mathrm{kN}$ (20 mm deflection at mid-span) with shear cracks observed in the shear span. Thereafter, with a large deformation, it failed at a loading of $789 \mathrm{kN}$ (152 mm deflection at midspan) showing the concrete crushed in the compression side near the loading point. Several splitting cracks were observed at the corner of the openings, but the FP2 specimen showed almost similar load-deflection behavior to that of specimen FP1 without web opening. The NLFEA evaluated the behaviors of specimens FP1 and FP2 very similarly and also provided accurate estimation on their yielding points and strengths. In Figures 10(a) and 10(b), the horizontal lines are the flexural capacities of specimens FP1 and FP2, respectively, estimated in accordance with EC4 [12]. It is shown that the proposed prestressed steel-concrete composite members with discontinuous webs can be designed by the EC4 model with a proper margin of safety.

4.3. Strain Distribution of Composite Section. The strain behaviors of specimens FP1 and FP2 measured at mid-span are compared with those estimated by NLFEA in Figures 11 and 12 . The measured strains were obtained from strain gauges mounted on the top and bottom surfaces of the concrete slab and those from strain gauges attached to the steel beam, as shown in the right side of Figures 11 and 12 in red and black. As illustrated in Figure 11, the bottom flange of the steel beam showed a yielding strain at a deflection level of about $23 \mathrm{~mm}$, which agreed well with the load-deflection behavior shown in Figure 10. The strain distributions obtained from the NLFEA showed similar behaviors to those observed in the tests, and, in particular, the analysis results well estimated the tensile strain behaviors measured at the gauge mounted on the soffit of the concrete slab. In Figure 13, the strain distribution of the DWPS composite beam estimated by NLFEA is presented, in which the tension zone below the neutral axis was expressed in the dark color to clearly distinguish it from the compressive zone. As shown in Figures 11(a) and 13(a), the strain distributions of both the concrete slab section (B-B section) and the central section of the composite beam (A-A section) were similar to each other; this is because the neutral axis was located lower than the soffit of the concrete slab before yielding of the bottom flange of the steel beam. After the yielding of the bottom flange, as shown in Figures 11(b) and 13(b), however, the neutral axis was located above the soffit of the concrete slab, and tensile strains also occurred in the concrete slab, while the top flange of steel beam did not experience such tensile strains. This deformation characteristic is caused by the accordion effect, developed in the steel beam with discontinuous web plates, which were captured by the NLFEA properly. The accordion effect of the test specimens observed after the composite action may have a negative effect on the flexural strength of the DWPS composite beam. However, its actual influence was insignificant; this is because the contributions of the top flange and the web to the flexural strength were relatively small compared with those of the bottom flange and the top slab. As shown in Figure 12, the behavioral characteristic of specimen FP2 with the opening was also very similar to that of specimen FP1. It is, however, noted that the strain increase measured at the soffit of the concrete slab of specimen FP2 was smaller than the F1 specimen. In contrast, the strains measured at the bottom steel flange of specimen FP2 were larger than that of specimen FP1 after its yielding, and this tendency appeared in both the analysis and test results. It is 


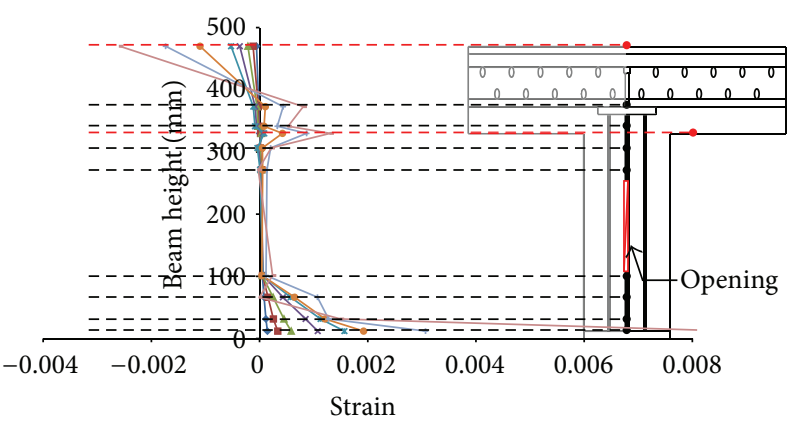

Deflection level

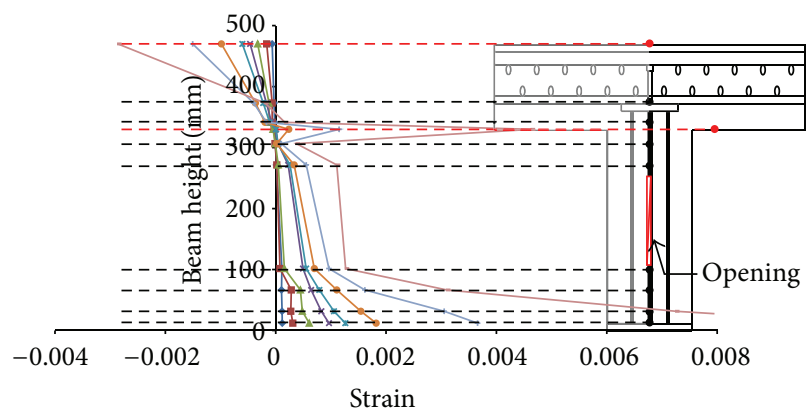

Deflection level

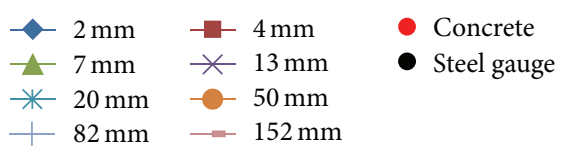

(a) Test results

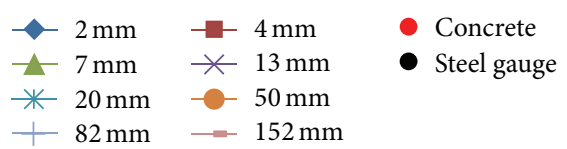

(b) FE analysis

FIGURE 12: Strain distribution along the sectional heights of specimen FP2.
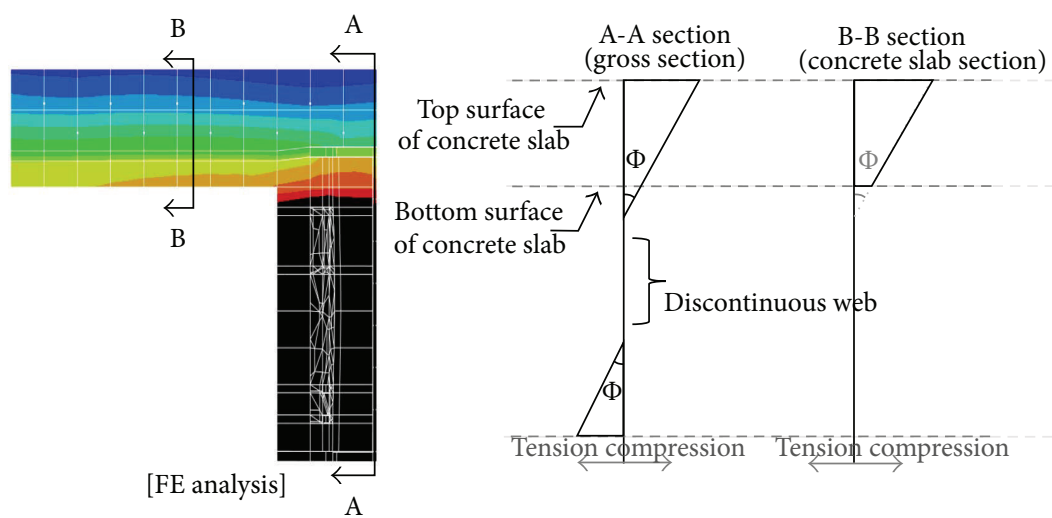

(a) Strain distribution before yielding of bottom flange

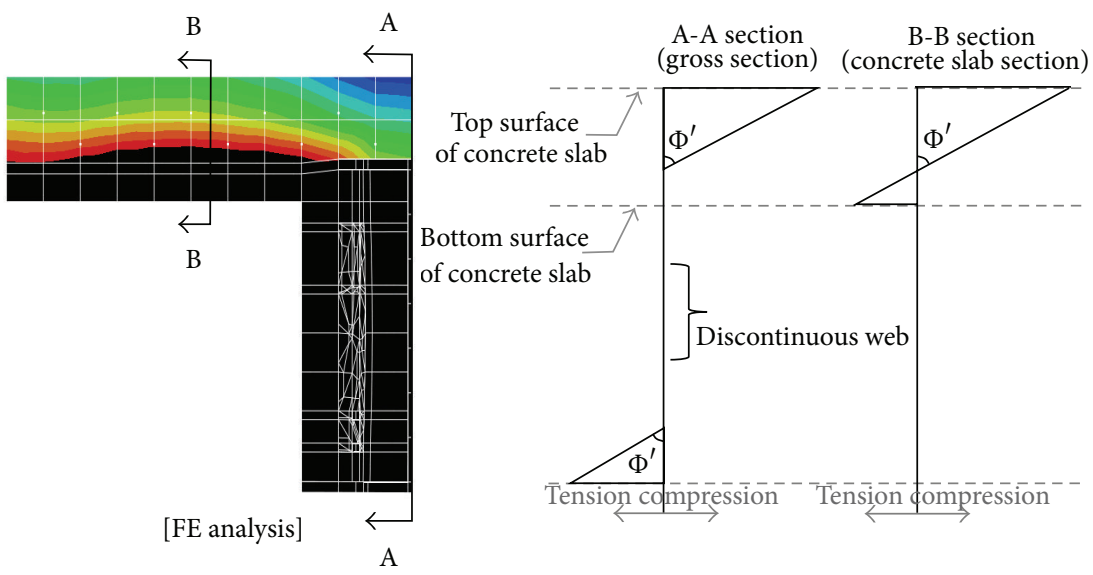

(b) Strain distribution after yielding of bottom flange

FIGURE 13: Comparison of strain distributions of composite section.

considered that the section area of the steel web reduced by the openings in the web plates caused the larger stresses in the bottom flange of specimen FP2 compared with the FP1 specimen.
4.4. Vertical Distribution of Shear Stress. The shear strength of the DWPS composite beam $\left(V_{n}\right)$ is provided mainly by the webs of steel and concrete. Thus, it can be expected that the web openings could have a significant influence 


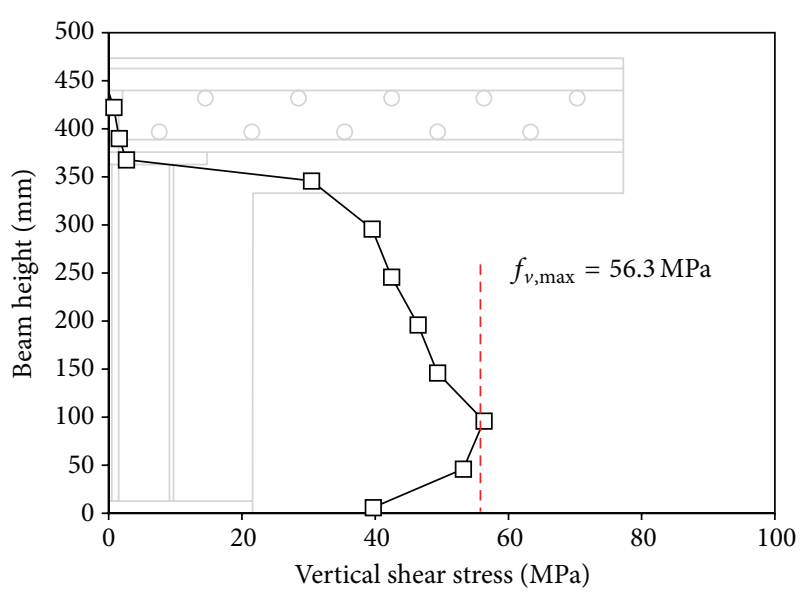

(a) Vertical shear stress distribution of FP1

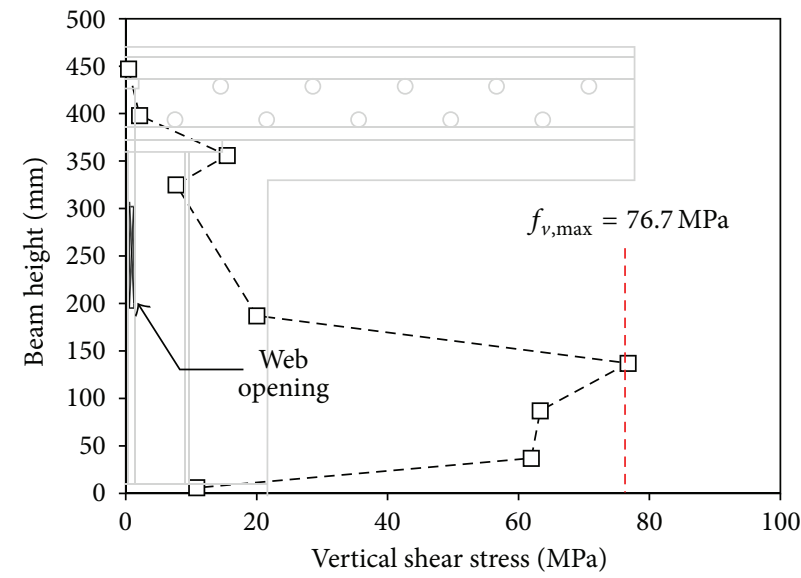

(b) Vertical shear stress distribution of FP2

FiguRE 14: Vertical shear stress distributions in transverse direction.

on its shear performance. To examine the effect of the web opening on the shear performance of the DWPS composite member, the distributions of shear stresses of specimens FP1 and FP2 at the maximum load estimated by the NLFEA are presented in Figure 14. It is noted that the shear stress distributions were calculated at the middle of shear span between the support and the loading point. The maximum shear stress values $\left(f_{v, \max }\right)$ of specimens FP1 and FP2 were 56.3 and $76.7 \mathrm{MPa}$, respectively, and by assuming a parabolic shear stress distribution, the ratio of the maximum shear stress $\left(f_{v, \max }\right)$ to the average shear stress of wide flange steel beam $\left(f_{v \text {,average }}\right)$ can be approximated to 1.1. Then, the shear resistance provided by the steel web plate $\left(V_{s, \text { FEA }}\right)$ can be estimated, as follows:

$$
V_{s, \mathrm{FEA}}=\frac{f_{v, \max }}{1.1} A_{w}
$$

where $A_{w}$ is the area of the steel web plate. On the other hand, in the AISC specification, the shear strength of a typical wide flange steel member is specified, as follows:

$$
V_{s, \mathrm{AISC}}=0.6 F_{y} A_{w} C_{v},
$$

where $C_{v}$ is the ratio of the critical web stress to the shear yield stress, which was taken to be 1.0 in this study. The shear resistance provided by the steel web $\left(V_{s, \mathrm{FEA}}\right)$ of specimens FP1 and FP2 was calculated with (6) as $252.2 \mathrm{kN}$ and $229.3 \mathrm{kN}$, respectively, while their shear strengths estimated using (7) were $1143.3 \mathrm{kN}$ and $881.2 \mathrm{kN}$, respectively. Thus, it can be confirmed that, regardless of the web openings, the shear strengths of the DWPS composite members are sufficient.

4.5. Horizontal Distribution of Shear Stress. Figure 15 shows the estimated distributions of the horizontal shear stresses developed in the longitudinal direction of the DWPS composite members along the interface between the concrete slab and the surface of top steel flange. At a small load level, below $589 \mathrm{kN}$, before yielding of the composite beam (i.e., at an elastic state), the specimens showed almost constant shear stress distributions, but after yielding of the composite beam, the horizontal shear stress near the loading point increased significantly. This is because the horizontal shear stresses resisted by the interface between the concrete slab and the top steel flange increased along with the moment increase and the plastic region was gradually expanded from the loading point (i.e., maximum moment region) after yielding of the composite beam. By comparing Figures 15(a) and 15(b), it can be seen that the influence of the web openings below the interface on the distribution of horizontal shear stress was insignificant.

\section{Conclusions}

In this study, the discontinuous-webbed prestressed composite beam was introduced, and its structural behaviors were examined in detail through experimental tests and FE analyses. Based on this study, the following conclusions were reached:

(1) The nonlinear finite element analysis (NLFEA) approach presented in this study was able to properly evaluate the structural behaviors of the discontinuous-webbed prestressed (DWPS) composite members, including the flexural strengths and the stiffness as well as the local behaviors.

(2) From the results of both the tests and the finite element analyses, it was confirmed that the introduction efficiency of prestress to the top and bottom flanges, which are the main flexural resistance elements, was greatly improved by using the accordion effect of the steel beam fabricated with the discontinuous webs.

(3) With reduced cross section of the steel web due to the openings, the shear stresses in the web steel plate are likely to be partially increased. Its effect was, however, 


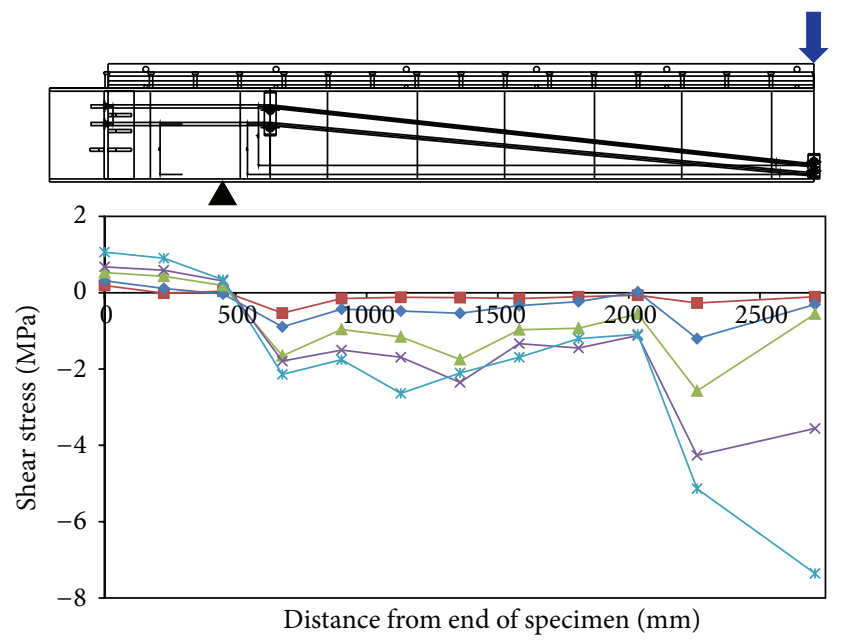

Load level

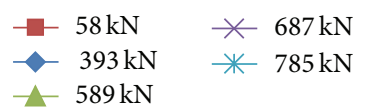

(a) FP1 specimen
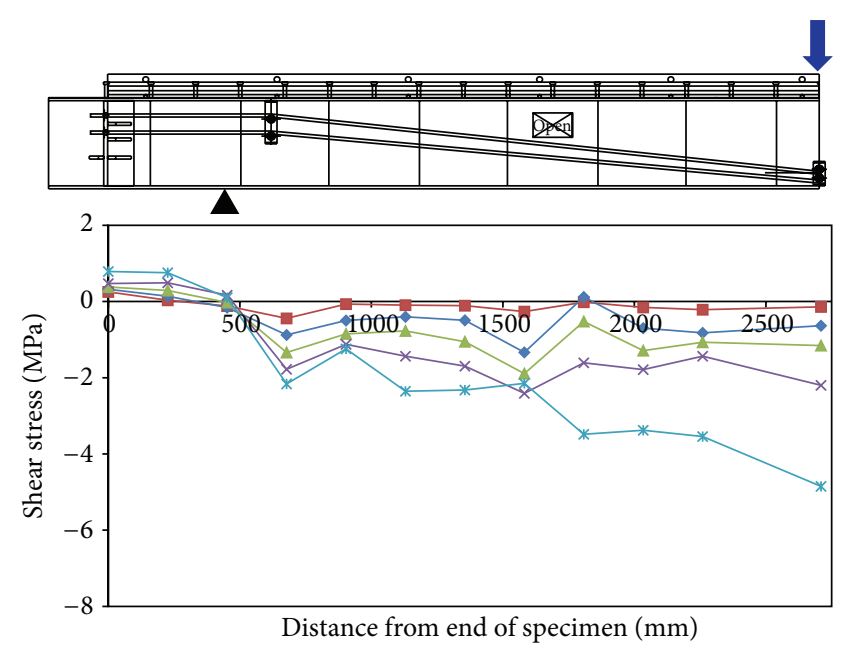

Load level

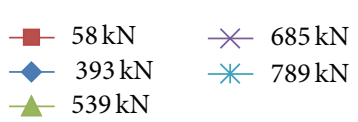

(b) FP2 specimen

FIGURE 15: Horizontal shear stress distribution estimated by FEA.

marginal, and sufficient safety can be achieved by considering the reduced cross section in the calculation of the shear strength of the DWPS composite member according to the design specification.

\section{Conflict of Interests}

The authors declare that there is no conflict of interests regarding the publication of this paper.

\section{Acknowledgment}

This research was supported by a grant (14Industrialization_Public Technology-03) from Technology Business Innovation Program funded by the Ministry of Land, Infrastructure and Transport Affairs of the Korean government.

\section{References}

[1] R. G. Driver, H. H. Abbas, and R. Sause, "Shear behavior of corrugated web bridge girders," Journal of Structural Engineering, vol. 132, no. 2, pp. 195-203, 2006.

[2] R. Sause, H. Abbas, B.-G. Kim, and R. Driver, "Innovative high performance steel bridge girders," in Proceedings of the Structures Congress and Exposition, Structures, ASCE, Reston, Va, USA, May 2001.

[3] R. Sause, H. Abbas, B.-G. Kim, R. Driver, and A. Smith, "Innovative high performance steel girders for highway bridges," in Proceedings of the Conference on High Performance Materials in Bridges and Buildings, pp. 309-318, Kona, Hawaii, 2001.

[4] J. T. Easley, "Buckling formulas for corrugated metal shear diaphragms," Journal of the Structural Division, vol. 101, no. 7, pp. 1403-1417, 1975.
[5] R. Luo and B. Edlund, "Buckling analysis of trapezoidally corrugated panels using spline finite strip method," Thin-Walled Structures, vol. 18, no. 3, pp. 209-224, 1994.

[6] H. H. Abbas, R. Sause, and R. G. Driver, "Analysis of flange transverse bending of corrugated web I-girders under in-plane loads," Journal of Structural Engineering, vol. 133, no. 3, pp. 347355, 2007.

[7] Y. A. Khalid, C. L. Chan, B. B. Sahari, and A. M. S. Hamouda, "Bending behaviour of corrugated web beams," Journal of Materials Processing Technology, vol. 150, no. 3, pp. 242-254, 2004.

[8] R. Mirghaderi, S. Sobhan, and S. Torabian, "Reducing beam section by corrugated webs for developing a connection of specially moment resisting frame," in Proceedings of the Structures Congress 2008: Crossing Borders, pp. 1-10, ASCE, Vancouver, Canada, April 2008.

[9] K. S. Kim, D. H. Lee, S. M. Choi, Y. H. Choi, and S. H. Jung, "Flexural behavior of prestressed composite beams with corrugated web: Part I. Development and analysis," Composites Part B: Engineering, vol. 42, no. 6, pp. 1603-1616, 2011.

[10] J.-Y. Oh, D. H. Lee, and K. S. Kim, "Accordion effect of prestressed steel beams with corrugated webs," Thin-Walled Structures, vol. 57, pp. 49-61, 2012.

[11] K. S. Kim and D. H. Lee, "Flexural behavior of prestressed composite beams with corrugated web. Part II. Experiment and verification," Composites Part B: Engineering, vol. 42, no. 6, pp. 1617-1629, 2011.

[12] D. H. Lee, J. Y. Oh, H. Kang, K. S. Kim, H. J. Kim, and H. Y. Kim, "Structural performance of prestressed composite girders with corrugated steel plate webs," Journal of Constructional Steel Research, vol. 104, pp. 9-21, 2015.

[13] S. E. Kim and H. T. Nguyen, "Finite element modeling and analysis of a hybrid steel-PSC beam connection," Engineering Structures, vol. 32, no. 9, pp. 2557-2569, 2010. 
[14] H. Hibbitt, B. Karlsson, and P. Sorensen, Abaqus Analysis Users Manual, Version 6.10, Dassault Systèmes Simulia, Providence, RI, USA, 2011.

[15] M. P. Collins and D. Mitchell, Prestressed Concrete Structures, Prentice Hall, Englewood Cliffs, NJ, USA, 1991.

[16] H. Kupfer, H. K. Hilsdorf, and H. Rusch, "Behavior of concrete under biaxial stresses," ACI Journal Proceedings, vol. 66, no. 8, pp. 656-666, 1969.

[17] A. A. Arab, S. S. Badie, and M. T. Manzari, "A methodological approach for finite element modeling of pretensioned concrete members at the release of pretensioning," Engineering Structures, vol. 33, no. 6, pp. 1918-1929, 2011.

[18] F. J. Vecchio and M. P. Collins, "The modified compression-field theory for reinforced concrete elements subjected to shear," ACI Journal Proceedings, vol. 83, no. 2, 1986. 

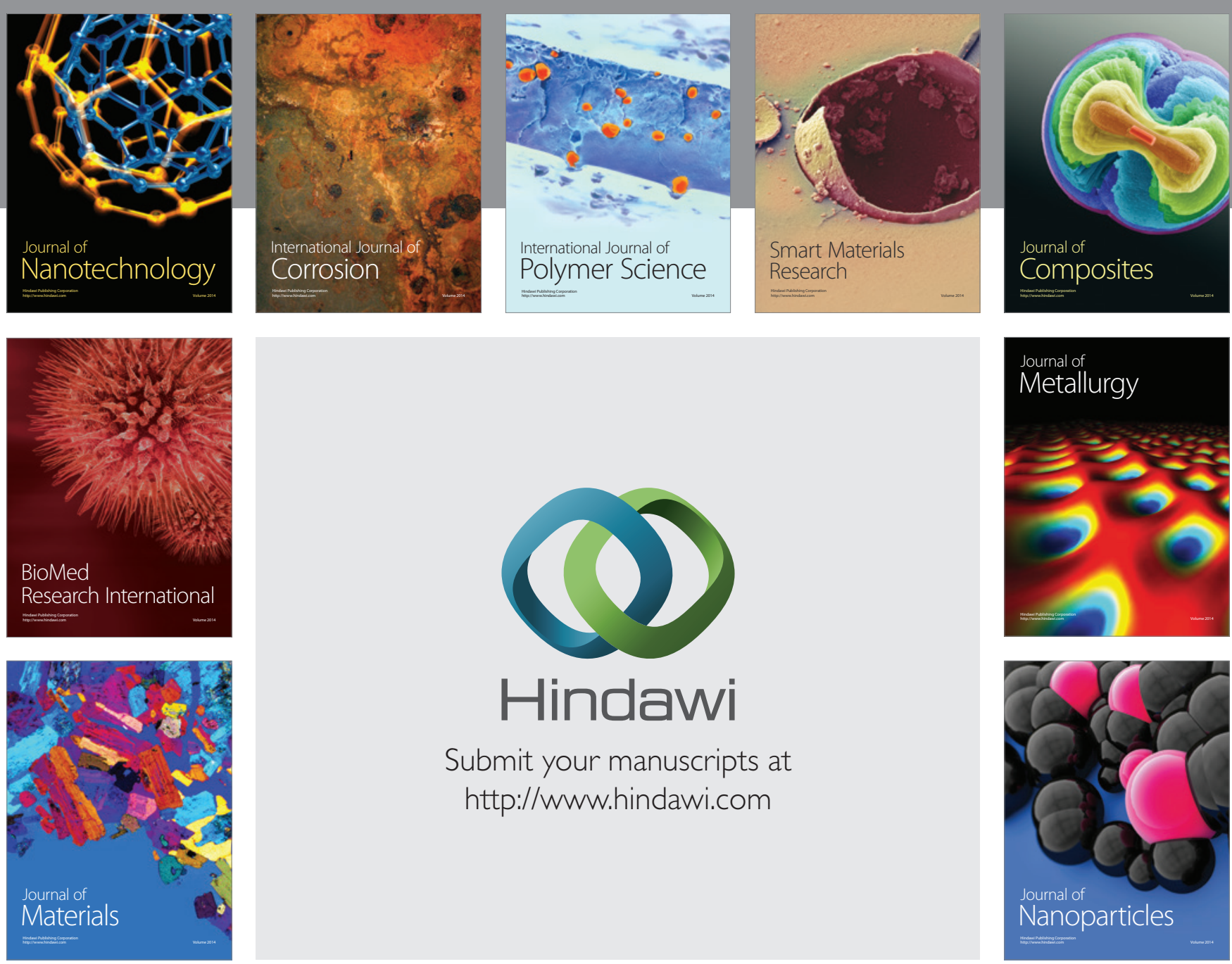

Submit your manuscripts at http://www.hindawi.com
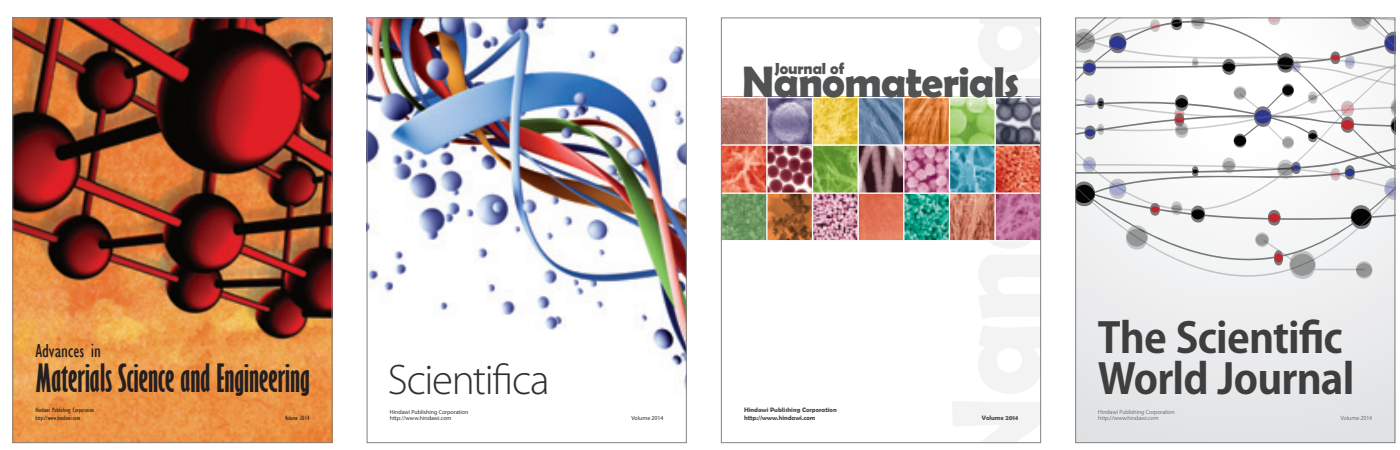

\section{The Scientific World Journal}
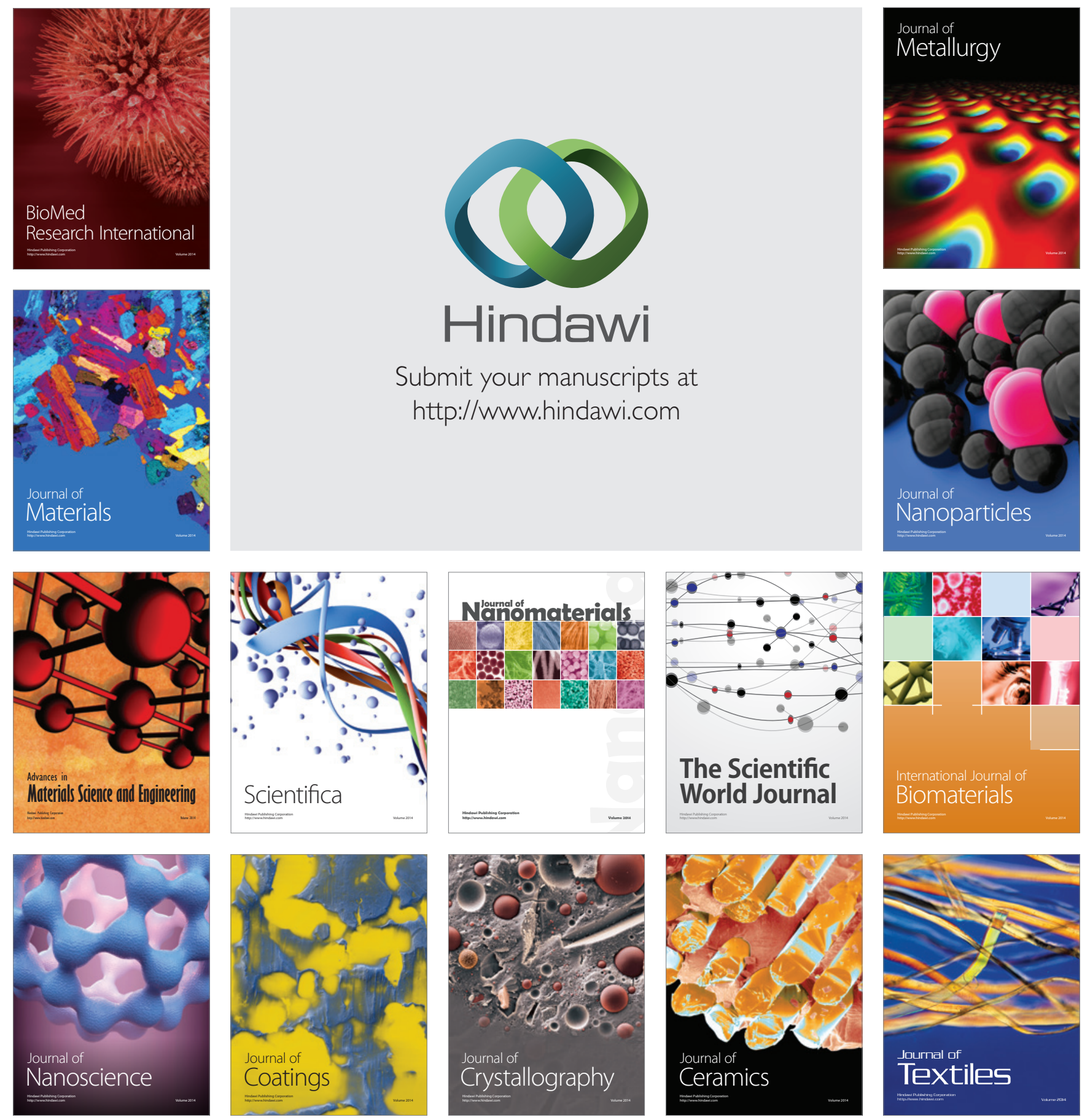